\title{
ETNOCONHECIMENTO COMO POTENCIALIDADE PARA OS NEGÓCIOS TURÍSTICOS: MICRO-ANÁLISE ETNOGRÁFICA DA COMUNIDADE DE TATAJUBA, CAMOCIM, BRASIL
}

\author{
*Aletusya de Araújo Benevides
}

\section{RESUMO:}

O objetivo do presente texto é apresentar o etnoconhecimento como um potencial para os negócios turísticos a partir da proposta de análise das redes institucionais da comunidade de Tatajuba, Camocim - Brasil. O estudo tem como referencial a teoria institucionalista de Douglass North, para quem as redes institucionais locais, as quais determinam as estratégias e regras em vigor no ambiente social da comunidade, devem ser compreendidas como determinantes básicas para o desenvolvimento.

\section{PALAVRAS-CHAVE:}

Etnoconhecimento; desenvolvimento sustentável; arranjos produtivos locais; teoria institucionalista

\section{ABSTRACT:}

The objective of the present text is to present ethnic knowledge as a potential for the tourism business based on the proposal of analysis of the institutional networks of the Tatajuba community in Camocim, Cerará, Brazil. The reference of the study is the institutionalist theory of Douglass North, for whom local institutional networks, which determine the strategies and rules in force in the social environment of the community, must be understood as basic determinatives for development.

\section{KEY WORDS:}

knowledge; cluster; sustainable development; institutionalist theory

\section{Introdução}

Sem a força das representações espaçotemporais, as sensibilidades que promovem as identidades são qualificadas em função do mercado, que veicula ordenações comportamentais efêmeras, ditadas de acordo com as oscilações que lhes são inerentes. A dificuldade de se firmar "linhas identitárias" não é uma negociação exclusiva do pesquisador, que julga seus documentos priorizando grupos mais ou menos coesos nas formas de exposição de suas sensibilidades e imaginários, e sim uma constante que faz com que priorizemos os termos múltiplos, ecléticos, heterogêneos; quadros vazios por não mais serem comportados numa idéia de meta-cultura. "A natureza social da identidade, do sentimento de pertencer ou de formas de apropriação do espaço que ela suscita, liga-se aos lugares habitados, marcados pela presença, criados pela história fragmentária feita de resíduos e detritos, pela acumulação dos tempos" (Carlos, 1996: 29). Apropriando-se da identidade como questão e partindo da premissa de que a sustentabilidade só é possível à medida em que 
sejam integrados os múltiplos saberes no processo de desenvolvimento, como potencializar os negócios turísticos integrando o etnoconhecimento ao processo de desenvolvimento econômico de uma dada região?

\section{A exemplo de Tatajuba}

A praia de Tatajuba está localizada no município de Camocim a 390 quilômetros a oeste de Fortaleza, capital do Ceará, possuindo, aproximadamente, 700 habitantes, distribuídos em quatro vilas, os quais vivem da atividade extrativista marinha, agricultura e criação de animais, além de pequenos comércios de gêneros de primeira necessidade. Geograficamente, é formada por mangues, lagoas permanentes e lagoas interdunares que, em algumas épocas do ano, e a depender da pluviosidade, unem-se ao mar. É formada, também, por dunas fixas e móveis, com alta vulnerabilidade à ocupação, justificada pelos "processos de transporte de sedimentos muito ativos e importantes para a manutenção da integridade da linha de costa" (AQUASYS, 2003: 31).

Desde 2001, a comunidade de Tatajuba tem enfrentado problemas que, em longo prazo, apresentam-se como uma ameaça ao desenvolvimento sustentável da região. A empresa Vitória Régia Empreendimentos Imobiliários Ltda., de capital português, está implantando o mega-projeto turístico "Condado Ecológico do Camocim", com capacidade para receber mil e quatrocentos turistas por semana. Em 1993, a empresa registrou no cartório do município uma propriedade equivalente a 5.275 hectares de terras, que inclui toda a extensão habitada, secularmente, pelos moradores daquela comunidade e áreas consideradas pela legislação brasileira como Áreas de Preservação Permanente, segundo o Instituto Brasileiro do Meio Ambiente e dos Recursos Naturais Renováveis/IBAMA. O que explica, a priori o registro recente de mais de treze mil acres de possessões é a prática da "grilagem", que, de acordo com a Plataforma Brasileira de Direitos Humanos, Econômicos, Sociais e Culturais DhESCA Brasil, "tem sido impulsionada pelo Programa de Desenvolvimento do Turismo do Nordeste do Brasil - PRODETUR/NE (l e II)" (DhESCA Brasil, 2004: 105).

A comunidade de Tatajuba tem se articulado no sentido de garantir o direito às terras e à manutenção das atividades extrativistas, as quais totalizam $90 \%$ da renda das famílias da região. Entretanto, os enfrentamentos entre comunidade e grupo de empresários explicitam a inobservância dos direitos e das demandas sociais e econômicas locais. O impacto social, cultural e ambiental que mega-projetos turísticos imprimem às áreas em que atuem é um fato já amplamente verificado pelo PRODETUR/NE I, que ao conferir milhões de reais para implantação de infra-estrutura comercial e turística, não contemplou nestes montantes as demandas internas das comunidades, tampouco considerou o etnoconhecimento que, historicamente, mantém a economia local a partir da sustentabilidade dos recursos naturais.

Se o "dever" do turismo, para a UNWTO, é o de assegurar atividades que forneçam, a todos os agentes, benefícios sócio-econômicos bem distribuídos, dando um ótimo uso aos recursos naturais e respeitando a autenticidade sócio-cultural das comunidades anfitriãs, contribuindo desta forma para o entendimento e a tolerância inter-culturais, a sustentabilidade só é possível à medida que sejam integrados os múltiplos saberes no processo de desenvolvimento.

A questão que se apresenta inicialmente, portanto, é como potencializar os negócios turísticos, integrando o etnoconhecimento da comunidade de pescadores de Tatajuba ao processo de desenvolvimento econômico da região litorânea de Camocim - Ceará, de forma a impulsionar a criação e o desenvolvimento de Arranjos Produtivos e Inovativos Locais? Tendo como objetivo o estudo do etnoconhecimento como um potencial para os negócios turísticos, 
Etnoconhecimento como potencialidade para os negócios turísticos:

micro-análise etnográfica da comunidade de Tatajuba, Camocim, Brasil, pp. 121 - 127

a micro-análise da comunidade de Tatajuba possibilita a formulação de um referencial teórico-prático sobre as características estruturais das redes institucionais que determinam as estratégias e regras em vigor no ambiente social da comunidade: Identificar as formas de apropriação do espaço e de direito de propriedade sobre o mesmo e sobre os recursos naturais, para a compreensão das variáveis envolvidas na formulação das propostas e projetos de desenvolvimento do turismo sustentável pela comunidade; Analisar a participação dos atores locais na identificação de problemas e na geração de soluções em função do processo de desenvolvimento turístico da região; Identificar o etnoconhecimento da comunidade em relação ao manejo e à produtividade dos recursos extrativistas marinhos; Identificar os arranjos culturais contidos nas argumentações adotadas pelos atores sociais da comunidade.

\section{Esferas Metodológicas}

As análises e os debates em torno das idéias correntes e conceitos diversificados, por vezes contraditórios, sobre turismo sustentável, impõem reflexões acerca das relações entre as comunidades dos destinos turísticos e as comunidades de turistas. A primeira, senão a mais difundida abordagem, identifica-as como categorias contrárias e conflitantes. Neste sentido, questões como valores, identidades e representações de mundo são submetidas a interpretações sócio-culturais, cujos interesses são vistos, a prioristicamente, como opostos. Isto dificulta a convergência de ações e métodos voltados para a identificação de possíveis interações, geradas a partir de diferentes e múltiplas competências fluídas de arranjos culturais e sociais entre contextos econômicos distintos, e cujas atividades predominantes são, de um lado, de aprovisionamento, de outro, de ordem urbano-industrial e informacional-global. (Camphora, 2004)

Deslocar o objeto a partir da reorganização de problematizações para além de categorias dicotômicas, incidindo numa investigação que busca apreender a multiplicidade e dinâmica das interações entre os diferentes atores e múltiplos agentes de promoção dos processos de desenvolvimento, revela-se como condição, primeiro, para a compreensão de um modelo de desenvolvimento sustentável; segundo, para a aplicação de mecanismos voltados a um desenvolvimento estratégico, os quais implicam na mobilização comunitária e na objetivação do o ambiente como um bem coletivo a ser preservado em suas dimensões econômica, ecológica e social (Irving apud Camphora, 2004), compreendendo, ambas, como condições para um Desenvolvimento Turístico que se quer Sustentável.

A operacionalização dos "deveres" do turismo, apontados pela UNWTO, expõe grandes e efetivos obstáculos que se interpõem à promoção da descentralização do poder decisório e, consequentemente, à participação efetiva das comunidades no processo de diagnóstico de problemas e planejamento de ações. O acesso privilegiado à informação universalizada, além de promover interligações econômicas, sociais e culturais num contexto globalizado, coloca as comunidades anfitriãs numa posição de inadequação/inaptidão às tomadas de decisões voltadas à promoção do desenvolvimento. A partir de uma análise dicotômica entre o local e o global, a comunidade receptora é interpretada como "despreparada", limitando-se sua participação na produção de informações e legitimização das propostas formuladas por agentes com base em referenciais externos à realidade local, provocando a estandardização e banalização das paisagens sócio-culturais, intimidando os processos participativos (Petersen, 1999).

Interpretar as comunidades de destino como incapazes de articulação e gerenciamento dos processos de decisão de quaisquer programas de desenvolvimento é, antes de tudo, renegar a cultura como uma atividade criativa e em constante processo de resignificação, outorgando a estas comunidades 
um papel de passivos receptores da estandartização promovida pelo mercado globalizado com sua produção de não-lugares. Contrariando tais apocalípticas assertivas, a observação que tomamos de empréstimo a Latour atenta que "as culturas supostamente em desaparecimento estão, ao contrário, muito presentes, ativas, vibrantes, inventivas, proliferando em todas as direções, reinventando seu passado, subvertendo seu próprio exotismo" (1996: 5). Por outro lado, outorgar à cultura, pura e simplesmente, a tarefa de equilibrar a dinâmica de correlação de forças que envolvem as relações entre mercado, política e organização social, é negligenciar a reorganização produtiva internacional e as conseqüências do acúmulo de riquezas, as quais promovem a recriação de signos de exclusão e inclusão, promovendo conflitos "culturais, religiosos, lingüísticos e raciais [resultando em] xenofobias, etnocentrismos, racismos, fundamentalismos, radicalismos, violências" (Ianni, 1996: 25).

Há de se apontar, por sua vez, que a quebra entre o comum, reconhecível, e o exótico, por si misterioso, promovida pela informação globalizada, que ao mundo interliga e às culturas resignifica, é o contrapeso que equilibra a balança. Ou seja, que o acesso à informação promovido pelo desenvolvimento das ferramentas comunicacionais e a expansão das relações mercadológicas traduz-se, necessariamente, num modus operandi de promoção de uma sociedade integrada a atual ordem mundial. Entretanto, o crescimento das conexões via satélite e suas ferramentas de acesso à internet, telefonia fixa e móvel, etc., são, circunstancialmente, fatores de inclusão e não essencialmente de integração social e econômica. Com um valor aproximado de $11,6 \%$ de analfabetos, o Brasil é um dos grandes exemplos de exclusão social, apesar de ocupar o 10ㅇ lugar no ranking mundial de conexões na internet $^{1}$. No Ceará, o percentual de analfabetos chega a atingir 56,8\% no município de Camocim, $66,3 \%$ no município de Jijoca de Jericoacoara e $69,94 \%$ no município de Barroquinha (ADHB,
2000), todos integrantes da Região IV incluídos no PRODETUR II como "regiões prioritárias para o turismo".

Programas de capacitação, articulação e consolidação de institucionalidades como os financiados pelo PNUD, BNDES, BNB etc., são vieses fundamentais para se estimular a inclusão social, o exercício da cidadania, a ampliação e diversificação das atividades econômicas e eficiência e eficácia da gestão pública. Mas, ao confrontar-se a realidade dos indicadores anteriormente descritos, o que se observa é uma incompatibilidade entre forma, método e objeto “Em geral, são programas de formulação genérica, centralizada, executados de maneira uniforme, sem maior preocupação com as diversas realidades locais. Nesses programas, o crédito disponível carece dos mesmos problemas de origem - formulação genérica e centralizada - não atendendo às diversidades regionais, de público e dos projetos produtivos"2. A otimização dos programas de capacitação depende, a priori, do gerenciamento de competências e habilidades diagnosticadas entre os atores envolvidos nos planos de desenvolvimento, haja visto que "a sustentabilidade acolhe aspectos materiais e imateriais das várias dimensões envolvidas em seu significado" (Irving e Camphora, 2005).

\section{As redes institucionais e a emergência do homem comum}

O conjunto de normas, usos e costumes, aspectos imateriais que guiam as relações humanas, oferece-nos amplas possibilidades de percepção das integrações e saberes entre o homem e o meio-ambiente. Esta estratégia de análise inter-relacional entre arranjos culturais, sociais e econômicos coloca as instituições, a organização e as representações mentais, capital social-, no centro do debate sobre Desenvolvimento Sustentável. Esta visão institucionalista do desenvolvimento parte da premissa de que a diminuição dos custos de uma economia e/ou a sustentabilidade da atividade 
Etnoconhecimento como potencialidade para os negócios turísticos:

micro-análise etnográfica da comunidade de Tatajuba, Camocim, Brasil, pp. 121 - 127

produtora "supõe que as condutas humanas sejam estabilizadas e minimamente previsíveis" (Abramovay, 2001: 3-4).

As populações, sobretudo as que promovem atividades artesanais e comunitárias de extração de recursos naturais, dependem, fundamentalmente, de um conjunto de recursos ligados a uma rede de relações institucionalizadas, organizando-se em torno de identidades comuns, traçando estratégias, excluindo e modificando regras à medida do jogo das necessidades. Instituições e organizações se coordenam e determinam as permanências e rupturas no seio da sociedade. E este movimento da história integra todas as instituições e inclui a visão que populações possuem do mundo natural, transmissão de conhecimento, religião e outros valores (Berkes, 1996). A atividade extrativista marinha não indica somente uma forma produtiva, mas também o estabelecimento de relações materiais e institucionais entre o homem e a natureza. A marcação do território para a atividade extrativista é regida por formas de pertencimento locais, as quais estabelecem uma multiplicidade de associações simbólicas no interior de cada comunidade. A escassez de uma dada espécie de peixe ou marisco, devido à natureza de cada ciclo reprodutivo, a pesca industrial predatória ou outros fenômenos, impelem os indivíduos a tomadas de decisões que podem manter ou alterar determinadas instituições vigentes na comunidade.

A marcação, própria da atividade artesanal, contrasta com a demarcação territorial, por ser aquela uma forma de apropriação espacial comunitária. Não diferente de outras sociedades, as respostas a uma dada situação dependem da co-relação existente entre aspectos da vida cultural, social e econômica. Entretanto "as respostas encontradas por sociedades locais para manutenção de seus modos de vida dependem das relações estabelecidas com o sistema dominante, e destacam-se como reflexões importantes para a compreensão da inserção da lógica utilizada por pescadores artesanais no que diz respeito aos recursos naturais por eles apropriados" (Chamy, 2005: 9). Os arranjos culturais locais, como a utilização de práticas tradicionais de pesca, de construção de embarcações, de aparelhos de pesca, etc., garantem não só a renda de $90 \%$ das famílias das localidades costeiras bem como uma altíssima qualidade dos produtos, onde o baixo índice de rendimento da pescaria é compensado pelo reduzido custo da operação, pela sustentabilidade dos recursos marinhos e pelo alto preço que o produto alcança no mercado, devido à comercialização do mesmo na forma in natura ou resfriada. Neste sentido, concordamos que “Um projeto de desenvolvimento deve considerar as potencialidades do meio sóciocultural no qual se insere. Os APL permitem explorar a capacidade de organização das redes locais, pré-existentes, e promover a inserção de outros agentes. Através dessas redes, muitas vezes, surgem oportunidades de articulação e aprendizagem interativa, aumentando o grau de sinergia, cooperação e de capacidade inovativa" (BNDES apud Haddad, 2004: 9).

A pesquisa participante (etnografia), como abordagem investigativa, possibilita estabelecer conhecimentos sobre as interações e as regras constituídas entre as sociedades e o meio-ambiente em que atuam, manifestados no cotidiano de representações firmadas por laços de pertencimento. A etnografia, à primeira vista, pode apresentar-se como uma contradição à abordagem institucional do desenvolvimento. Entretanto, o interesse na abordagem comparativa é um interesse na abordagem holística de uma determinada interação, ação ou resposta de um dado grupo em relação a um todo daquela sociedade. O que, num primeiro momento, pode parecer reações contraditórias e conflitantes a um mesmo fenômeno, envolve na verdade, interações particularmente ligadas às instituições expressas nas formas de organização de um dado capital social e cultural e suas representações. Neste sentido "participar" é interpretar, hermeneuticamente, o significado das ações para o próprio grupo, e não o 
proceder de análise meramente comparativa entre um dado "eu" e o "outro".

A análise do discurso desta com unidade, como método de investigação científica etnográfica, incide sobre a análise holística da cultura vista com o um sistem a de significados próprios das socialidades hum anas, colbcando os atores sociais com o dbjto e sujitto do processo de desenvolvin ento do conhecin ento. A proposta de trabaho é um a m icro-análise sócio-arluraldas redes e relações estabelecidas na com unidade de Tatajuba, tendo como foco prim ário a Associação Com unitária dos Moradores de Tatajuba, a priori compreendida como uma instituição representativa formal que expressa as demandas legítimas de seus detentores. No que se pretende apreender as materialidades, suas leis consuetudinárias, as formas de coordenação das ações e as representações mentais que regulamentam a vida daquela sociedade.
Ao se colocar a análise das interrelações institucionais como meio legítimo para o processo de desenvolvimento econômico, afirma-se, também, que suas organizações e representações podem implicar nas políticas governamentais, criando oportunidades de desenvolvimento e enfrentamento da pobreza, e que a viabilização da participação efetiva dos atores sociais está condicionada ao acesso à informação e capacidade de gerenciamento da mesma em função de seus dispositivos culturais e organizacionais. Menos que apontar valores, identidades e representações de mundo como categorias contrárias e conflitantes, é perceber a informação e organização social, presentes nas comunidades dos destinos turísticos, como mecanismos potenciais na integração dos arranjos sociais e culturais locais ao processo de desenvolvimento econômico.

\section{Notas}

${ }^{1}$ Fonte: Nielsen/NetRatings. Usuários domésticos. In: Dados Estatísticos sobre a internet e o comércio eletrônico. Disponível em http://www.ecommerce.org.br/STATS.htm\#D.
2 BNDES / PNUD - Programa de Desenvolvimento Local. Disponível em http:// www.bnds.gov.br

\section{Bibliiografia}

ABRAMOVAY, Ricardo. “Desenvolvimento e instituições: a importância da explicação histórica". In - ARBIX, Glauco, ZILBOVICIUS, Mauro e ABRAMOVAY, Ricardo. Razões e ficções do desenvolvimento: UNESP/EDUSP, 2001.

ADHB. Atlas do Desenvolvimento Humano no Brasil. Ano 2000. Disponível em http:// www.undp.org.br/hdr/atlas.htm.

AQUASYS (Associação de Pesquisa e Preservação de Ecossistemas Aquáticos). A Zona Costeira do Ceará: diagnóstico para a gestão integrada. Fortaleza, 2003.
BENEVIDES, Aletusya de Araújo. A estética do Consumo no Cenário Social e Cultural da Praia de Iracema. Rio de Janeiro: Papel Virtual, 2005.

BERKES, Fikret. "Social systems, ecological systems, and property rights". In: Rights to nature: ecological, economic, cultural and political principles of institutions for the environment. Washington: Island Press, 1996.

CAMPHORA, Ana Lúcia. "Comunidades receptoras locais e comunidades de turistas: redimensionando responsabilidades para um turismo sustentável". In: Boletim Técnico do SENAC/ Serviço Nacional de Aprendizagem 
Etnoconhecimento como potencialidade para os negócios turísticos:

Comercial. Administração Nacional. Vol. 30, n. 1, jan./abr., 2004.

CARLOS, Ana Fani Alessandri. O turismo e a produção do não-lugar. In: YÁZIGI, Eduardo, CARLOS, Ana Fani Alessandri e CRUZ, Rita de Cássia (Org.). Turismo: paisagem, espaço e cultura. São Paulo: Hucitec, 1996.

CHAMY, Paula. Reservas Extrativistas Marinhas como instrumento de reconhecimento do direito consuetudinário de pescadores artesanais brasileiros sobre territórios de uso comum. PROCAM/NUPAUB/USP, 2005.

CORIOLANO, Luiza Neide Menezes Teixeira (organizadora). O Turismo de Inclusão e o desenvolvimento local. Fortaleza, CE: Funece, 2003.

DhESCA Brasil. Relatorias Nacionais em Direitos Humanos, Econômicos, Sociais e Culturais: informe 2004.

HADDAD, Paulo. Seminário do BNDS sobre Arranjos Produtivos Locais: texto de referência da palestra sobre cultura local e Associativismo.
Belo Horizonte, setembro de 2004. Disponível em: < www.bndes.gov.br/conhecimento/ seminario/apl >

IANNI, Octávio. A era do globalismo. Rio de J aneiro: Civilização Brasileira, 1996.

IRVING, Maria de Azevedo. “Turismo, ética e educação ambiental - novos paradigmas em planejamento". In: IRVING, M. A. e AZEVEDO, J. Turismo: o desafio da sustentabilidade. São Paulo, SP: Futura, 2002.

LATOUR, Bruno. "Not the Question". Anthropology Newsletter, 37(3): 1-5, 1996.

NORTH, Douglass. Institutions, institucional change and economic performance. Cambridge: Cambridge University Press, 1990.

PETERSEN, Paulo. “Participação e desenvolvimento agrícola participativo: uma visão estratégica com ênfase na etapa do diagnóstico". In: PETERSEN, P.; ROMANO, J.O. (Orgs.) Abordagens participativas para o desenvolvimento local. Rio de Janeiro: ASPTA/ Actionaid Brasil, 1999. 
